\title{
Prevalence of obesity and overweight in school going adolescents of Surat city, Gujarat, India
}

\author{
Sonal Sureshbhai Gamit, Mohua Moitra, Mamta Rani Verma \\ Department of PSM, Government Medical College, Surat, Gujarat, India. \\ Correspondence to: Sonal Sureshbhai Gamit, E-mail: sgamit77@yahoo.com \\ Received August 8, 2014. Accepted August 29, 2014
}

\section{Abstract}

Background: The prevalence of obesity is increasing with the changing lifestyle of families over the past few years.

Objectives: To study the prevalence and review specific parameters contributing to obesity in schoolgoing adolescents.

Materials and Methods: A cross-sectional study was carried out among purposively selected schools of different socioeconomic strata in Surat city after taking their due permission. A predesigned, semi-structured questionnaire was administered to the students in the 14-16 years age group and filled under supervision. Data were collected from 1079 school adolescents within 8 months, from January 2013 to August 2013. Physical parameters such as height, weight, and waist and hip circumference were measured. Analysis was carried out using Epi Info 6 and appropriate statistical tests (proportions, $\chi^{2}$-test) were applied.

Results: Overall prevalence of overweight and obesity was $10.2 \%$ and $6 \%$, respectively. The prevalence of overweight and obesity was $12.4 \%$ and $8.2 \%$ in boys whereas it was $7.2 \%$ and $2.7 \%$ in girls. The majority of overweight (17.7\%) and obese students $(11.2 \%)$ were from upper income group (UIG) schools compared to lower income group (LIG) schools in which $7.4 \%$ students were found to be overweight and $4.2 \%$ were found to be obese, and middle income group (MIG) school in which $6.3 \%$ students were overweight and $3 \%$ were obese. This difference in body mass index (BMI) among three groups was statistically significant $(p<0.00)$. More cases of overweight and obesity were found in students whose parents had higher level of education $(p<0.00)$. Association was found between parents' occupation and BMI $(p<0.05)$. Obesity $(7.2 \%)$ and overweight $(12.5 \%)$ were seen more in children using vehicular transport for going to school.

Conclusion: Prevalence of overweight and obesity was more in students in UIG as compared to MIG and LIG schools. A significant association was found between parents' education, occupation, mode of transportation to school, and BMI. Awareness generation regarding lifestyle-related diseases prevalent among the adolescents and parents is need of the hour.

KEY WORDS: prevalence, obesity, adolescent, schoolgoing

\section{Introduction}

Prevalence of obesity, which is presently seen as a defined cluster of non-communicable diseases, is observed in both developed and developing nations. The global epidemic of obesity is a reflection of massive social, economic, and cultural problems. ${ }^{[1]}$

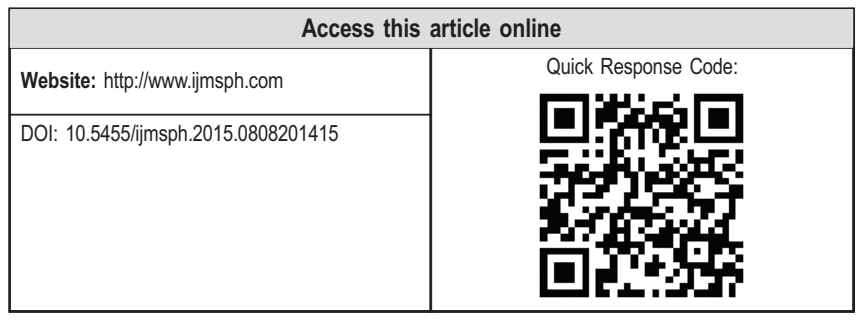

Obesity is increasingly being associated with the changing lifestyle of families as a result of increased purchasing power and increased inactivity due to television, video games, and computers, which have replaced outdoor games and other social activities. ${ }^{[2]}$

World Health Organization has defined obesity as a disease in which excess body fat accumulates to an extent that health may be adversely affected. The underlying cause is the processes of undesirable positive energy balance and weight gain. ${ }^{[1]}$

Overweight and obesity are the fifth leading causes of global deaths. As obesity is preventable ${ }^{[1,3]}$; it is one of the challenges of the 21 st century. ${ }^{[4]}$

Worldwide obesity has more than doubled since 1980. In addition, $44 \%$ of the diabetes burden, $23 \%$ of the ischemic heart disease burden, and between $7 \%$ and $41 \%$ of certain cancer burdens are attributable to overweight and obesity. 
More than 1.4 billion adults 20 years and older are overweight. Approximately 35 million overweight children are living in developing countries and 8 million in developed countries. ${ }^{[3]}$ Thus, addressing obesity should be a priority.

Overweight in adolescence is a marker of overweight in adult age, and is associated with the diseases such as diabetes mellitus and cardiovascular disease. ${ }^{[5]}$ A study conducted by Alok et al. ${ }^{[6]}$ in urban and rural areas of Surat city in the 14-16 years age group found the prevalence of obesity to be $12.8 \%$ in rural and $14.6 \%$ in urban adolescents. JP Goyal et al. ${ }^{[7]}$ conducted a study on the prevalence of obesity in adolescents aged 12-15 years and RK Goyal et al. ${ }^{[8]}$ conducted a study in adolescents aged $12-18$ years belonging to different socioeconomic status (SES) in Surat. The study data were collected to measure the prevalence of obesity in the adolescents aged 14-16 years and to review specific causes contributing to overweight and obesity. The authors also studied the relationship of obesity with type of family, religion, parents' education and occupation, and mode of conveyance to school among adolescents studying in selected schools of Surat city.

\section{Materials and Method}

It was a cross-sectional study carried out in purposively selected schools from January 2013 to August 2013. The sample size was calculated keeping in mind the prevalence rate of overweight $17 \%$ and $10 \%$ allowable error.

Inclusion Criteria: All adolescents aged 14-16 years willing to participate in the study and studying in one of the seven selected schools and who were present during the time of study conduction.

Exclusion Criteria: Adolescents aged 14-16 years who do not agree to participate in the study and who were absent during the time of conduction of the study.

Purposive sampling of 976 subjects after sample size calculations was carried out. Assuming a nonresponse rate of $10 \%$, the sample size was 1076 . Information was collected from 1079 adolescents. After identifying and selecting the schools, we obtained permission from District Education Officer (DEO). As per information shared by the principal, the average annual income of parents was as follows: Upper income group (UIG) schools, > 6-7 lacs; middle income group (MIG) schools, 1-2 lacs, and in lower income group (LIG) schools, $<25,000 /$ year. The questionnaire was shared with the school authorities and informed written consent was obtained.

Once questionnaire was approved, data were collected on sociodemographic profile of the students, physical parameters such as height, weight, and waist/hip ratio were measured. Student who had body mass index (BMI) of $>85$ th and $<95$ th percentile of reference population were classified as overweight and BMI of $>95$ th percentile of reference population were classified as obese. Schools who gave permission were selected and after identifying standard, subsections of standard randomly selected (lottery method) and interviewed through the pretested semi-structured questionnaire. Data were analyzed using MS Excel 2007 and Epi Info 6 software for calculating proportions and $\chi^{2}$-tests. Proportions were used for variables such as age, BMI category, waist/hip ratio, religion, father and mother's education and occupation, and mode of conveyance to school. $\chi^{2}$-Test was applied to BMI category and different SES, waist/hip ratio in girls, religion, education and occupation, and mode of conveyance to school.

\section{Permission for the Study}

Permission for the study was obtained from the Human Research Ethics Committee of the Government Medical College, Surat.

\section{Results}

A total of 1079 participants were studied, out of which 636 $(58.9 \%)$ were boys and $443(41.1)$ girls. Median age of the students was 15 years with a standard deviation of 0.75 years. Majority 169 (49.9\%) of the students were in UIG, 171 (42.2\%) students who were in MIG were of 14 years of age, whereas $132(39.4 \%)$ students in LIG school were aged 15 years (Table 1).

In different age groups, mean height and weight was consistently more in boys compared to girls. BMI was found to increase with age in boys. In girls, it was found to increase in the 15-year age group and decreased in the 16-year age group. In all the different age groups, the mean waist circumference was more in boys compared with girls but the hip circumference was more in girls compared to boys (Table 2).

Table 1: Age- and sex wise distribution of study population in different schools

\begin{tabular}{lcccccccccc}
\hline \multirow{2}{*}{ Age } & \multicolumn{3}{c}{ UIG school $(\mathbf{n}=\mathbf{3 3 9})$} & \multicolumn{2}{c}{ MIG school $(\mathbf{n}=\mathbf{4 0 5})$} & \multicolumn{2}{c}{ LIG school $(\mathbf{n}=\mathbf{3 3 5})$} \\
\cline { 2 - 9 } & Boys (\%) & Girls (\%) & Total $(\%)$ & Boys (\%) & Girls (\%) & Total (\%) & Boys (\%) & Girls (\%) & Total (\%) & Grand total \\
\hline 14 & $128(49.4)$ & $41(51.2)$ & $169(49.9)$ & $69(34)$ & $102(50.5)$ & $171(42.2)$ & $60(34.5)$ & $51(31.7)$ & $111(33.1)$ & $451(41.8)$ \\
15 & $103(39.8)$ & $35(43.8)$ & $138(40.7)$ & $91(44.8)$ & $57(28.2)$ & $148(36.5)$ & $66(37.9)$ & $66(41)$ & $132(39.4)$ & $418(38.7)$ \\
16 & $28(10.8)$ & $4(5)$ & $32(9.4)$ & $43(21.2)$ & $43(21.3)$ & $86(21.3)$ & $48(27.6)$ & $44(27.3)$ & $92(27.5)$ & $210(19.5)$ \\
Total & $259(100)$ & $80(100)$ & $339(100)$ & $203(100)$ & $202(100)$ & $405(100)$ & $174(100)$ & $161(100)$ & $335(100)$ & $1079(100)$ \\
\hline
\end{tabular}

(Figure in parenthesis indicates percentage) 
Table 2: Data on anthropometric variables

\begin{tabular}{|c|c|c|c|c|c|c|c|}
\hline Sex & Age (year) & No & $\begin{array}{l}\text { Height(cm), } \\
\text { mean(SD) }\end{array}$ & $\begin{array}{l}\text { Weight(kg), } \\
\text { mean(SD) }\end{array}$ & $\begin{array}{l}\text { BMI }\left(\mathrm{kg} / \mathrm{m}^{2}\right) \\
\text { Mean (SD) }\end{array}$ & $\begin{array}{c}\text { Waist } \\
\text { circumference }(\mathrm{cm}) \text {, } \\
\text { mean(SD) }\end{array}$ & $\begin{array}{c}\text { Hipcircumference }(\mathrm{cm}) \text {, } \\
\text { mean (SD) }\end{array}$ \\
\hline \multicolumn{3}{|c|}{ Overall (boys and girls) } & 157.31 (8.66) & $46.76(11.95)$ & $18.76(3.89)$ & $69.24(10.46)$ & $83.5(9.82)$ \\
\hline \multicolumn{3}{|l|}{ Boys } & 157.31 (8.66) & $46.76(11.95)$ & $18.76(3.89)$ & $69.24(10.46)$ & $83.5(9.82)$ \\
\hline \multicolumn{8}{|c|}{ Boys (age wise) } \\
\hline & 14 & $257(40.4)$ & $157.17(9.31)$ & $46.18(12.43)$ & $18.49(3.86)$ & $70.92(11.20)$ & $81.84(11.25)$ \\
\hline & 15 & $260(40.9)$ & 161.32 (8.46) & 49.12 (13.76) & $18.69(4.29)$ & $71.69(11.16)$ & $83.64(10.65)$ \\
\hline & 16 & 119 (18.7) & $163.63(8.46)$ & $52.15(13.25)$ & $19.39(4.39)$ & $72.43(10.56)$ & $84.39(10.07)$ \\
\hline & Total & 636 & & & & & \\
\hline \multicolumn{8}{|c|}{ Girls (age wise) } \\
\hline \multirow[t]{3}{*}{ Girls } & & & 157.27 (8.66) & 46.69 (11.93) & $18.74(3.9)$ & $69.2(10.46)$ & 83.48 (9.83) \\
\hline & 14 & $194(43.8)$ & $152.64(6.15)$ & $42.62(9.58)$ & $18.23(3.72)$ & $65.77(8.54)$ & $82.83(8.24)$ \\
\hline & 15 & $158(35.7)$ & $153.55(5.66)$ & $46.05(8.97)$ & $19.51(3.54)$ & $67.30(8.83)$ & $85.56(8.16)$ \\
\hline
\end{tabular}

Overall prevalence of overweight and obesity was $111(10.3 \%)$ and 64 (5.9\%), respectively. Prevalence of overweight and obesity was $79(12.4 \%)$ and $52(8.2 \%)$ in boys and $32(7.2 \%)$ and $12(2.7 \%)$ in girls (Table 3$)$.

In UIG students, $60(17.7 \%)$ were overweight and $38(11.2 \%)$ were obese when compared with $25(7.4 \%)$ overweight and $14(4.2 \%)$ obese from LIG, and $26(6.3 \%)$ overweight and $12(3 \%)$ obese from MIG schools. This difference was also statistically significant $(p<0.00)$. Waist/hip ratio was more in girls when compared to boys. In the UIG schools, $29(36.2 \%)$ girls; in the LIG 27 (16.8\%) girls and in the MIG $10(5 \%)$ girls had more waist/hip ratio when compared to boys, which was found to be statistically significant ( $p=0.001$; Table 4).

Among all religions, obesity (16.7\%) and overweight (20.8\%) were found to be more among Christians ( $p=0.00$; Table 5).

Overweight $14(11.3 \%)$ and obese $10(8.1 \%)$ students were seen more in joint families, but there was no statistical association between family type and BMI ( $p=0.55$; Table 5).

The rate of overweight $(31 \%)$ and obesity $(24.6 \%)$ was higher in students whose fathers had higher level of education. Similarly, higher prevalence of overweight (34.4\%) and obesity $(24.9 \%)$ was found in the students whose mother had higher level of education, and the results were statistically significant $(p<0.00$; Table 5).

Table 3: Categorization of BMI among boys and girls according to IAP criteria

\begin{tabular}{lccc}
\hline BMI category & Boys & Girls & Total \\
\hline Underweight & $99(15.6)$ & $66(14.9)$ & $165(15.3)$ \\
Normal & $406(63.8)$ & $333(75.2)$ & $739(68.5)$ \\
Overweight & $79(12.4)$ & $32(7.2)$ & $111(10.3)$ \\
Obese & $52(8.2)$ & $12(2.7)$ & $64(5.9)$ \\
Total & $636(100)$ & $443(100)$ & $1079(100)$ \\
\hline
\end{tabular}

Among studied population, $30(9.1 \%)$ obese and 48 (14.5\%) overweight students' father were doing business. Among all, 12 (16.4\%) overweight and 10 (13.7\%) obese students' mothers were in service and $8.1 \%$ obese and $10.5 \%$ overweight students' mothers were doing business or were housewives. There was significant association between father's and mother's occupation and overweight and obesity ( $p=0.001$; Table 5).

Higher rates of obesity $(7.2 \%)$ and overweight $(12.5 \%)$ were seen in children going to school in vehicle compared to those who went on foot (obese, $5.4 \%$; overweight $(8.8 \%)$ and on a cycle (obese, $2.4 \%$; overweight, $5.5 \%$ )). Statistically significant association was found between the mode of conveyance to school and BMI ( $p=0.00$; Table 5).

\section{Discussion}

In this study, the prevalence of overweight (11.3\%) and obesity $(8.1 \%)$ was found to be higher in joint families, but there was no statistical association between family type and BMI ( $p=0.55$; Table 5$)$. As shown by National Family Health Survey (NFHS-III) ${ }^{[9]}$ report, three of five households in India are nuclear. The household structure shows that proportion of nuclear households is higher in urban areas $(63 \%)$. Similarly, rates of approximately $67.6 \%$ nuclear and $32.4 \%$ joint families were reported by Bharati et al. ${ }^{[10]}$ In a study carried out by Keerthan et al. ${ }^{[11]}$, no significant association was found between type of family and obesity, but the percentage of overweight $(3.11 \%)$ and obesity $(4.15 \%)$ was much higher in children staying in nuclear family than joint family $(1.89 \%$ and $1.42 \%$ ).

In this study, $54 \%$ students went to school by vehicle; $30.7 \%$ on foot; and $15.3 \%$ by bicycle. Higher proportion of obese $(7.2 \%)$ and overweight $(12.5 \%)$ children were going to school using a vehicle compared to those who went on foot 
Table 4: Profile of physical parameters BMI and waist/hip ratio of the study population

\begin{tabular}{|c|c|c|c|c|c|c|c|c|c|c|}
\hline & \multicolumn{3}{|c|}{ UIG school } & \multicolumn{3}{|c|}{ MIG school } & \multicolumn{3}{|c|}{ LIG school } & \multirow[t]{2}{*}{$p$-Value } \\
\hline & $\begin{array}{c}\text { Boys, } \\
n=259\end{array}$ & $\begin{array}{c}\text { Girls, } \\
n=80\end{array}$ & $\begin{array}{c}\text { Total } \\
n=339\end{array}$ & $\begin{array}{c}\text { Boys, } \\
n=203\end{array}$ & $\begin{array}{c}\text { Girls, } \\
n=202\end{array}$ & $\begin{array}{c}\text { Total } \\
n=405\end{array}$ & $\begin{array}{c}\text { Boys, } \\
n=174\end{array}$ & $\begin{array}{c}\text { Girls, } \\
n=161\end{array}$ & $\begin{array}{c}\text { Total } \\
n=335\end{array}$ & \\
\hline \multicolumn{11}{|c|}{ BMI (according to IAP growth reference) } \\
\hline Underweight & $17(6.6)$ & $10(12.5)$ & $27(8)$ & $52(25.6)$ & $41(20.3)$ & $93(23)$ & $30(17.2)$ & $15(9.3)$ & $45(13.4)$ & $\chi^{2}=82$ \\
\hline Normal & $157(60.6)$ & $57(71.3)$ & $214(63.1)$ & $126(62.1)$ & $148(73.3)$ & $274(67.7)$ & $123(70.7)$ & $128(79.5)$ & $251(75)$ & $\mathrm{df}=6<0.00$ \\
\hline Overweight & $51(19.7)$ & $9(11.2)$ & $60(17.7)$ & $15(7.4)$ & $11(5.4)$ & $26(6.3)$ & $13(7.5)$ & $12(7.5)$ & $25(7.4)$ & \\
\hline Obese & $34(13.1)$ & $4(5)$ & $38(11.2)$ & $10(4.9)$ & $2(1)$ & $12(3)$ & $8(4.6)$ & $6(3.7)$ & $14(4.2)$ & \\
\hline \multirow{2}{*}{\multicolumn{2}{|c|}{ Waist/hip ratio }} & \multicolumn{4}{|c|}{ Boys } & \multicolumn{4}{|c|}{ Girls } & \\
\hline & & UIG & MIG & LIG & - & UIG & MIG & LIG & $\chi^{2}=44.98$ & \\
\hline Normal & & $259(100)$ & $201(99)$ & $173(99.4)$ & & $51(63.8)$ & $192(95)$ & $134(83.2)$ & $\mathrm{df}=2<0.001$ & \\
\hline More & & $0(0.0)$ & $2(1)$ & $1(0.6)$ & & $29(8.6)$ & $10(5)$ & $27(16.8)$ & & \\
\hline
\end{tabular}

(obesity, 5.4\%; overweight, $8.8 \%$ ) and by cycle (obesity, $2.4 \%$; overweight, $5.5 \%)$. Statistically significant association was found between the mode of conveyance and BMI $(p=0.00$; Table 5). Similar findings were reported by Laxmaiah et al., ${ }^{[12]}$ the prevalence of overweight was significantly lower $(p<0.05)$ among adolescents who either walked to school 130 or came on bicycle $(6.4 \% ; 95 \% \mathrm{Cl}: 4.9-8.1)$ than among the adolescents who used vehicular transport such as motorcycles or cars $(9.9 \% ; 95 \% \mathrm{Cl}$ : 6.4-13.4). Similarly, Goyal et al. ${ }^{[7]}$ reported that $7.6 \%$ students go to school by walking/ bicycle whereas $92.4 \%$ use auto/bus. In the same study, transport to school by bus or auto was also associated with 2.81 times (OR: $2.81 ; 95 \% \mathrm{Cl} 1.41-5.61$ ) increased risk of overweight and obesity.

In this study, the prevalence of overweight (31\%) and obesity $(24.6 \%)$ was higher in students whose fathers had higher level of education. Higher prevalence of overweight $(34.4 \%)$ and obesity (24.9\%) was found in students whose mother had higher level of education. Significant statistical association was found between overweight and obesity and parents' education $(p<0.00)$. This could be due to higher income among more educated fathers, which may have resulted in associated lifestyle factors related to higher income. Probably the reason is that more affluence leads to easy money and lack of time, influencing food choices. Among students whose fathers were professionals, $11.8 \%$ were obese and $23.5 \%$ were overweight; among those whose fathers were businessmen, $9.1 \%$ were obese and $14.5 \%$ were overweight. There was a significant association between fathers' occupation and overweight and obesity $(p=0.0001)$. In the present study, majority $(84 \%)$ of the mothers were housewives followed by $(6.8 \%)$ doing service; $63(5.8 \%)$ doing other work; and $(3.4 \%)$ doing business. Of the total population, $16.4 \%$ overweight and $13.7 \%$ obese students' mothers were doing service, and $8.1 \%$ obese students' mothers were doing business and $10.5 \%$ overweight students' mothers were housewives. There is association between mothers' occupation and overweight and obesity ( $p=0.01$; Table 5). Similar findings were reported by Laxmaiah et al. ${ }^{[12]}$ that prevalence of overweight was significantly higher $(p>0.05)$ among the adolescents whose parents' occupation was either service $(9.1 \%)$ or business $(7.4 \%)$ than other occupations $(3.1 \%)$. Bharati et al. ${ }^{[10]}$ found that the risk of overweight/obesity was significantly higher among children whose father and mother had education more than sixth standard, and children whose fathers were service/businessmen. Similarly, Adesina et al. ${ }^{[13]}$ found that the percentage of overweight subjects whose mothers were highly educated was higher $(9.7 \%)$. These findings were also supported by Majeed et al. ${ }^{[14]}$ showing that highest percentage of the study girls were the offspring of highly educated (college and more) mothers (46.86\%). However, high percentages $(72.6 \%)$ of the population under study reported their mothers to be housewives

In this study, in all age groups mean height and mean weight were higher in boys compared to girls. BMI was found increasing with age in boys whereas it was observed increasing in 15th year and decreasing in 16th year in girls (Table 2). Similarly, Goyal et al. ${ }^{[8]}$ observed that height, weight, and BMI were higher in boys than girls. Similarly Raj et al. ${ }^{[15]}$ reported that mean height, weight, and BMl were increasing in both boys and girls aged from 14 to 16 years.

In this study, overall prevalence of overweight and obesity was $10.3 \%$ and $5.9 \%$, respectively. The prevalence of overweight and obesity was $79(12.4 \%)$ and $52(8.2 \%)$ in boys, and $32(7.2 \%)$ and $12(2.7 \%)$ in girls (Table 3$)$. Goyal et al. ${ }^{[7]}$ reported the overall prevalence of obesity and overweight to be $6.55 \%$ and $13.9 \%$ in their study conducted in Surat city. The prevalence of obesity and overweight was $6.7 \%$ and $15.1 \%$ in boys and $6.4 \%$ and $13.3 \%$ in girls. The prevalence of obesity and overweight was more in boys compared to girls, but the difference was very small and statistically nonsignificant. Similarly, Keerthan et al., ${ }^{[11]}$ and Kaur et al. ${ }^{[16]}$ observed that the prevalence of obesity and overweight was higher in boys compared to girls.

In this study, 60 (17.7\%) and $38(11.2 \%)$ students from UIG school were found to be overweight and obese, respectively, 
Table 5: Relationship of BMI with socioeconomic factors

\begin{tabular}{|c|c|c|c|c|c|c|}
\hline & \multicolumn{6}{|c|}{ BMI } \\
\hline & Obese & Overweight & Normal & Underweight & Total & $p$-Value \\
\hline \multicolumn{7}{|l|}{ Religion } \\
\hline Hindu & $34(9.8)$ & $53(15.2)$ & $225(64.7)$ & $36(10.3)$ & $348(32.3)$ & $\chi^{2}=43.35^{\star}$ \\
\hline Muslim & $25(3.6)$ & $51(7.4)$ & $490(70.9)$ & $125(18.1)$ & $691(64)$ & $\mathrm{df}=6<0.00$ \\
\hline Christian & $4(16.7)$ & $5(20.8)$ & $14(58.3)$ & $1(4.2)$ & $24(2.2)$ & \\
\hline \multicolumn{7}{|l|}{ Type of family } \\
\hline Nuclear & $38(5.3)$ & $79(11)$ & $489(68.1)$ & $112(15.6)$ & $718(66.5)$ & $\chi^{2}=4.91$ \\
\hline Joint & $10(8.1)$ & $14(11.3)$ & $80(64.5)$ & $20(16.1)$ & $124(11.5)$ & $\mathrm{df}=60.55$ \\
\hline Extended & $16(6.8)$ & $18(7.6)$ & $170(71.7)$ & $33(13.9)$ & $237(22)$ & \\
\hline \multicolumn{7}{|l|}{ Father's education } \\
\hline Illiterate & $5(3.6)$ & $7(5)$ & $101(72.1)$ & $27(19.3)$ & $140(13)$ & $\chi^{2}=53.24$ \\
\hline Primary and secondary & $21(3.8)$ & $45(8.1)$ & $393(70.6)$ & $98(17.6)$ & $557(51.6)$ & $\mathrm{df}=9<0.00$ \\
\hline Postgraduate and above & $15(16.7)$ & $14(15.6)$ & $51(56.7)$ & $10(11.1)$ & $90(8.3)$ & \\
\hline \multicolumn{7}{|l|}{ Mother's education } \\
\hline Illiterate & $6(3)$ & $10(5)$ & $151(74.8)$ & $35(17.3)$ & $202(18.7)$ & $\chi^{2}=50.99$ \\
\hline Primary and secondary & $24(4.2)$ & $52(9.1)$ & $394(69.1)$ & $100(17.5)$ & $570(52.8)$ & $\mathrm{df}=9<0.00$ \\
\hline Higher secondary and Undergraduate & $24(10)$ & $36(15)$ & $158(65.8)$ & $22(9.2)$ & $240(22.2)$ & \\
\hline Postgraduate and above & $10(14.9)$ & $13(19.4)$ & $36(53.7)$ & $8(11.9)$ & $67(6.3)$ & \\
\hline \multicolumn{7}{|l|}{ Father's occupation } \\
\hline Professional & $4(11.8)$ & $8(23.5)$ & $18(52.9)$ & $4(11.8)$ & $34(3.2)$ & $\chi^{2}=47.63$ \\
\hline Service & $13(4.9)$ & $29(11)$ & $175(66.6)$ & $46(17.5)$ & $263(24.4)$ & $\mathrm{df}=180.0001$ \\
\hline Business & $30(9.1)$ & $48(14.5)$ & $213(64.5)$ & $39(11.8)$ & $330(30.6)$ & \\
\hline Small business & $3(2.8)$ & $2(1.8)$ & $88(80.7)$ & $16(14.7)$ & $109(10.1)$ & \\
\hline Driver & $6(4.1)$ & $14(9.6)$ & $99(67.8)$ & $27(18.5)$ & $146(13.5)$ & \\
\hline Laborer & $4(4.1)$ & $3(3.1)$ & $74(75.5)$ & $17(17.3)$ & $98(9.1)$ & \\
\hline Others & $4(4)$ & $7(7.1)$ & $72(72.2)$ & $16(16.2)$ & $99(9.2)$ & \\
\hline Service & $10(13.7)$ & $12(16.4)$ & $43(58.9)$ & $8(11)$ & $73(6.8)$ & $\mathrm{df}=60.01$ \\
\hline Business & $3(8.1)$ & $2(5.3)$ & $23(62.2)$ & $9(24.3)$ & $37(3.4)$ & \\
\hline Others & $1(1.6)$ & $2(3.2)$ & $47(74.6)$ & $13(20.6)$ & $63(5.8)$ & \\
\hline \multicolumn{7}{|l|}{ Mode of conveyance to school } \\
\hline Walking & $18(5.4)$ & $29(8.8)$ & $227(68.6)$ & $57(17.2)$ & $331(30.7)$ & $\chi^{2}=22.51$ \\
\hline Bicycle & $4(2.4)$ & $9(5.5)$ & $115(69.7)$ & $37(22.4)$ & $165(15.3)$ & $\mathrm{df}=60.00$ \\
\hline Other* & $42(7.2)$ & $73(12.5)$ & $397(68.1)$ & $71(12.2)$ & $583(54)$ & \\
\hline
\end{tabular}

${ }^{*}$ Christian and other religion merged when $\chi^{2}$-test applied

*Mothers occupation service and business merged when $\chi^{2}$-test applied

*Other modes of conveyance to school were scooter, bus, auto, car, etc.

as compared to $25(7.4 \%)$ and $14(4.2 \%)$ from LIG, and 26 $(6.3 \%)$ and $12(3 \%)$ from MIG school. This difference was also statistically significant $(p<0.00$; Table 4$)$. Kaur et al. ${ }^{[16]}$ observed that the prevalence of obesity and overweight in LIG schoolchildren was $0.1 \%$ and $2.7 \%$, respectively; among MIG schoolchildren, it was $0.6 \%$ and $6.5 \%$; and among high income group schoolchildren it was $6.8 \%$ and $15.3 \%$ $(p<0001)$. In contrast, Goyal et al. ${ }^{[8]}$ reported that the prevalence of overweight among children was high in middle SES as compared to high SES group in both the genders; however the prevalence of overweight was the lowest in the low SES group. By contrast, prevalence of obesity was higher in high SES group as compared to middle SES group.

\section{Conclusion}

The prevalence of overweight and obesity was higher in students belonging to UIG as compared to those belonging to LIG and MIG, and was still higher in boys compared to girls. In all age groups, mean height and weight were more in boys 
compared to girls. BMI was found to be increasing with age in boys whereas in girls it was found increasing in 15th year and decreasing in the 16th year. Significant association was found between parent's education and occupation status and overweight and obesity among students $(p<0.00)$. In all age groups, mean waist circumference was higher in boys as compared to girls whereas mean hip circumference was higher in girls as compared to boys. Waist/hip ratio was higher in girls as compared to boys. Because purposive sampling technique was used, the results cannot be generalized.

\section{References}

1. World Health Organization. Obesity: Preventing and Managing the Global Epidemic. WHO Consultation on Obesity. 1998. Available at: http://whqlibdoc.who.int/hq/1998/WHO_NUT_NCD_ 98.1_(p1-158).pdf.

2. Singh $M$, Sharma M. Risk factor for obesity in children. Indian Pediatr 2005;42:183-5.

3. World Health Organization. WHO Fact Sheet. 2012. Available at: http://www.who.int/mediacentre/factsheets/fs311/en/.

4. World Health Organization. World Health Statistics. 2012. Available at: http://www.who.int/gho/publications/world_health_statistics/EN_ WHS2012_Full.pdf.

5. Ramachandran A, Snehalatha C, Vinitha R, Thayyil M, Kumar CK, Sheeba $\mathrm{L}$, et al. Prevalence of overweight in urban Indian adolescent school children. Diabetes Res Clin Pract 2002;57(3):185-90.

6. Parekh A, Parekh M, Vadasmiya D. Prevalence of overweight and obesity in adolescents of urban and rural area of Surat , Gujarat Natl J Med Res 2012;2(3):325-9.

7. Goyal JP, Kumar PN, Indira P, Vijay SB, Patel PB. Determinants of overweight and obesity in affluent adolescent in Surat city, South Gujarat region, India. Indian J Community Med 2011;36 (4):296-300.

8. Goyal RK, Shah VN, Saboo BD, Phatak SR, Shah NN, Gohel MC, et al. Prevalence of overweight and obesity in Indian adolescent school going children: its relationship with socioeconomic status and associated lifestyle factors. J Assoc Physicians India 2010;58:151-8

9. International Institute for Population Sciences (IIPS) and Macro International. National Family Health Survey (NFHS-3), 2005-06: India: Volume I. Mumbai: IIPS, 2007.

10. Bharati DR, Deshmukh PR, Garg BS. Correlates of overweight and obesity among school going children of Wardha city, Central India. Indian J Med Res 2008;127(6):539-43.

11. Keerthan Kumar M, Prashanth K, Baby KE, Rao KR, Kumarkrishna B, Hegde K, et al. Prevalence of obesity among high school children in Dakshina Kannada and Udupi districts. Nitte Univ J Heal Sci 2011;1(4):16-20.

12. Laxmaiah A, Nagalla B, Vijayaraghavan $K$, Nair M. Factors affecting prevalence of overweight among 12- to 17-year-old urban adolescents in Hyderabad, India. Obesity (Silver Spring). 2007;15(6):1384-90.

13. Adesina AF, Peterside O, Anochie I, Akani NA. Weight status of adolescents in secondary schools in port Harcourt using Body Mass Index (BMI). Ital J Pediatr 2012;38:31.

14. Majeed BA, Al-Kubaisy W, Al-Hameed AA. Knowledge, attitude, and practices of adolescent school girls towards dietary habits and physical activity. 1-27. Available at: http://www.genderclearinghouse.org/upload/Assets/Documents/pdf/5BanAdoSchoolGirl Baghdad.pdf.

15. Raj M, Sundaram KR, Paul M, Deepa AS, Kumar RK. Obesity in Indian children: time trends and relationship with hypertension. Natl Med J India 2007;20(6):288-93.

16. Kaur S, Sachdev HPS, Dwivedi SN, Lakshmy R. Prevalence of overweight and obesity amongst school children in Delhi, India. Asia Pac J Clin Nutr 2008;17(4):592-6.

How to cite this article: Sureshbhai GS, Moitra M, Verma MR. Prevalence of obesity and overweight in school going adolescents of Surat city, Gujarat, India. Int J Med Sci Public Health 2015;4:42-47

Source of Support: Nil, Conflict of Interest: None declared. 